\title{
Symptomatic retention of the patency capsule: a multicenter real life case series
}

Authors

Institutions
Uri Kopylov ${ }^{1, *}$, Artur Nemeth ${ }^{2, *}$, Alba Cebrian ${ }^{3}$, Gabriele Wurm Johansson ${ }^{2}$, Henrik Thorlacius ${ }^{2}$ Ignacio Fernandez-Urien Sainz ${ }^{3}$, Anastasios Koulaouzidis ${ }^{4}$, Rami Eliakim ${ }^{1}$, Ervin Toth ${ }^{2}$

Institutions are listed at the end of article. submitted 26. April 2016 accepted after revision 5. July 2016

\section{Bibliography}

Dol http://dx.doi.org/

10.1055/s-0042-112588

Published online: 8.8.2016

Endoscopy International Open 2016; 04: E964-E969

(c) Georg Thieme Verlag KG E-ISSN 2196-9736

\section{Corresponding author}

Department of

Gastroenterology

Sheba Medical Center

Tel Hashomer

Ramat Gan

Israel

Fax: +972-3-53031600 Stuttgart · New York Uri Kopylov, MD

ukopylov@gmail.com

Background and aims: The patency capsule is designed to evaluate the patency of the small bowel before administration of small-bowel capsule endoscopy (SBCE) in patients at high risk of retention. The utilization of a patency capsule may be associated with a risk of symptomatic retention, but very few cases have been reported to date. The aim of our study was to describe our experience with this rare complication of a patency capsule.

Methods: This was a multicenter retrospective case series. The medical records of patients who underwent a patency capsule test were scanned and all cases of symptomatic retention were collected.

\section{Introduction \\ $\nabla$}

Small-bowel video capsule endoscopy (SBCE) is a prime modality for diagnosis of small-bowel [1 4] pathology such as obscure gastrointestinal bleeding (OGIB), small-bowel tumors and inflammation [5]. It plays an important role in both the diagnosis and monitoring of small-bowel Crohn's disease (CD) [1 - 8]. However, one of the main limiting factors in the use of SBCE in patients with established $C D$ is the risk of capsule retention, which has been reported to be as high as $13 \%$ in early studies $[9,10]$, although in more recent series, the risk of retention was much lower [1116]. In patients with established $C D$, assessment of small-bowel patency by cross-sectional imaging or patency capsule is recommended [7].

The patency capsule (Given Imaging, Yokneam, Israel) is a non-diagnostic capsule of the same shape and dimensions as the diagnostic capsule ( $\bullet$ Fig. 1). The cellophane-walled capsule cylinder, filled with lactose admixed with barium, is protected by hollow plugs allowing influx of

\section{License terms}

\section{()(1) $\Theta \circledast$}

* These authors contributed equally.
Results: In total, 20 symptomatic cases of retention out of 1615 (1.2\%) patency capsule tests were identified; in one patient, the patency capsule was retained in the esophagus, in the rest, the capsule was detected in the small bowel resulting in abdominal pain or small-bowel obstruction. One patient (5\%) required surgery; all other patients resolved spontaneously or after corticosteroid therapy.

Conclusions: Symptomatic patency capsule retention is a very rare complication with a favorable prognosis. It should be recognized but its use in patients with suspected small-bowel stenosis should not be discouraged.

intestinal fluid leading to dissolution of the lactose. In addition to barium which allows radiological detection, the patency capsule contains an inner RFID tag which enables detection by a handheld radiofrequency scanner (HHS) [3]. Successful excretion or non-detectability of the ingested patency capsule in a predefined time ( 40 hours for the 1 st generation and 30 hours for the 2 nd generation) patency capsule indicates that a diagnostic SBCE can be safely performed $[1,7]$. Complications from a patency capsule are very rare; only a handful of cases, presenting with symptoms ranging from mild abdominal pain to full-blown small-bowel obstruction, have been reported to date $[8,17-22]$.

The aim of the current study is to describe our multicenter experience with symptomatic cases of patency capsule retention.

\section{Methods}

$\nabla$

A retrospective chart review was performed to identify patients with symptomatic patency capsule retention (defined as symptoms of abdominal pain/vomiting) combined with detection of 


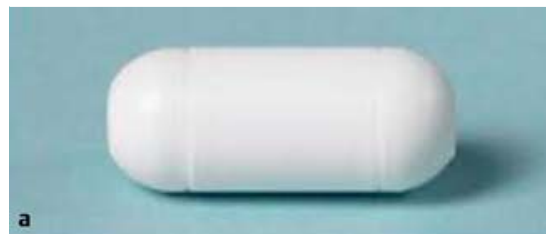

Fig. 1 Second generation patency capsule before ingestion (a) and upon excretion 60 hours after ingestion (b).

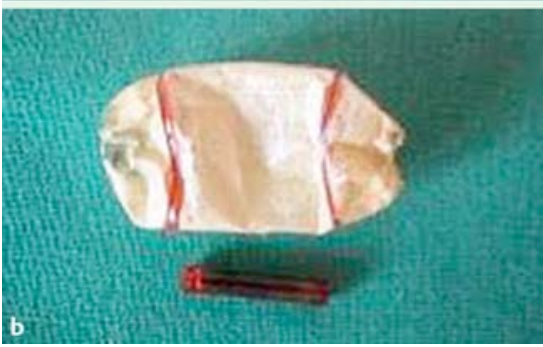

the patency capsule in the small bowel by plain abdominal film (XR), computed tomography (CT), or HHS within or after the defined excretion time.

\section{Results}

$\nabla$

A total of 1615 patency capsule examinations were registered in the clinical databases of the participating centers (between June 2005 and December 2015). In total, 20 cases of symptomatic patency capsule retention were identified (1.2\%). In one patient, the patency capsule was retained in the esophagus, while in the rest, it was retained in the small bowel.

The patency capsule examination was performed in 19 patients for suspected $(6 / 20,30 \%)$ or established $(13 / 20,65 \%) \mathrm{CD}$, and in one patient for a suspected mesenteric ischemic event. Six patients (30\%) had a previous history of abdominal surgery; 7 (35\%) had previous episodes of small-bowel obstruction (SBO); $2(10 \%)$ patients had used nonsteroidal anti-inflammatory drugs (NSAIDs) at least once within the preceding 12 months. Two $(10 \%)$ of the patients had undergone previous radiotherapy. In one patient, a M2A capsule was used, and in the remainder, the Agile patency capsule was used.

All patients with a retained capsule presented with abdominal pain; in 14 of them (70\%), the presentation was accompanied by overt symptoms of clinical small-bowel obstruction (vomiting, abdominal distension, failure to pass stool or gas). The median time from patency capsule ingestion to diagnosis was 9 hours (interquartile range (IQR) 8-24 hours). The patency capsule was detected by HHS in 9 (45\%) of the patients; small-bowel location was confirmed by XR ( $\bullet$ Fig. 2 ) and CT ( $\bullet$ Fig. 3 ) in three patients each; in one patient with dysphagia, the patency capsule was detected by HHS and later discovered in the esophagus and advanced to the duodenum by esophagogastroduodenoscopy. In the remainder of the patients, HHS was not used and the patency capsule was detected either by XR or CT directly.

The symptoms resolved spontaneously within up to 72 hours in $13(65 \%)$ patients. Five $(20 \%)$ patients were treated with systemic corticosteroids with subsequent resolution within up to 1 week. One patient required ileocecal resection and in another, the patency capsule, which was retained in the esophagus due to a Schatzki ring, was advanced to the duodenum endoscopically. This patient underwent diagnostic SBCE (introduced endoscopically) that was normal and uneventful.

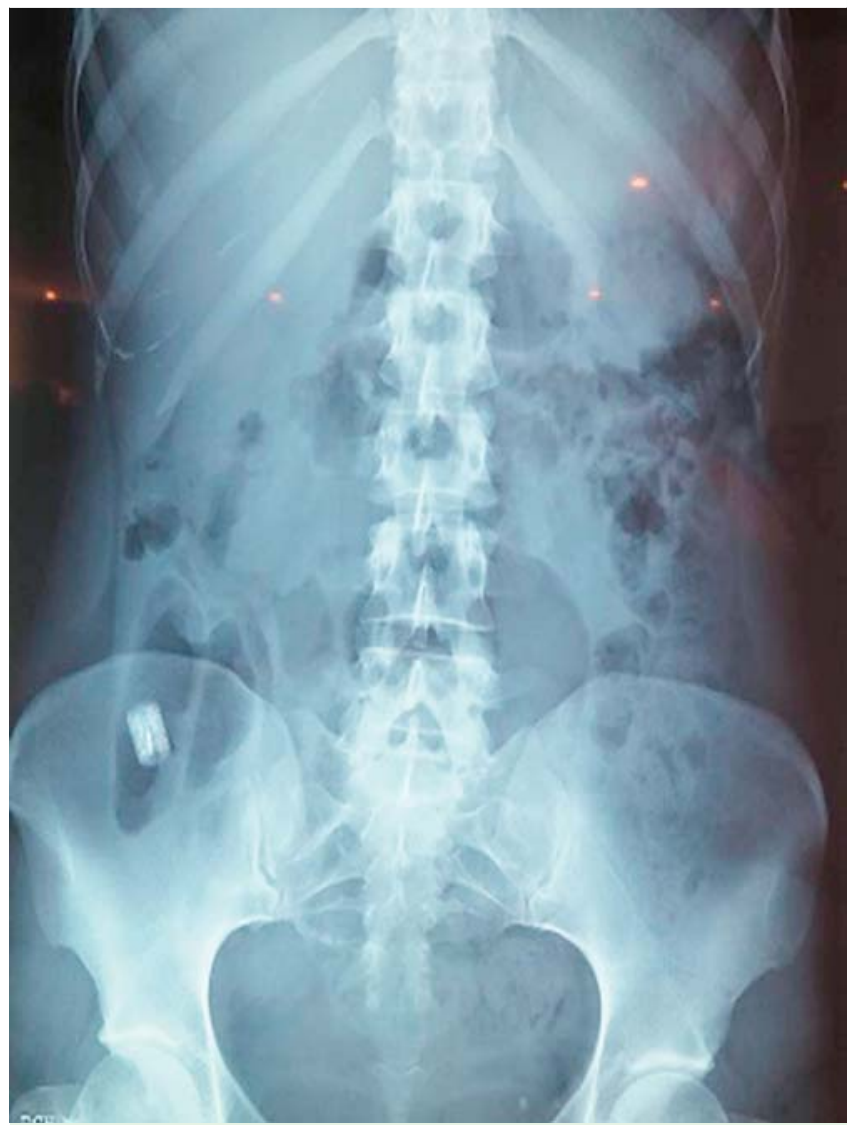

Fig.2 Plain abdominal X-ray: patency capsule in the right iliac fossa.

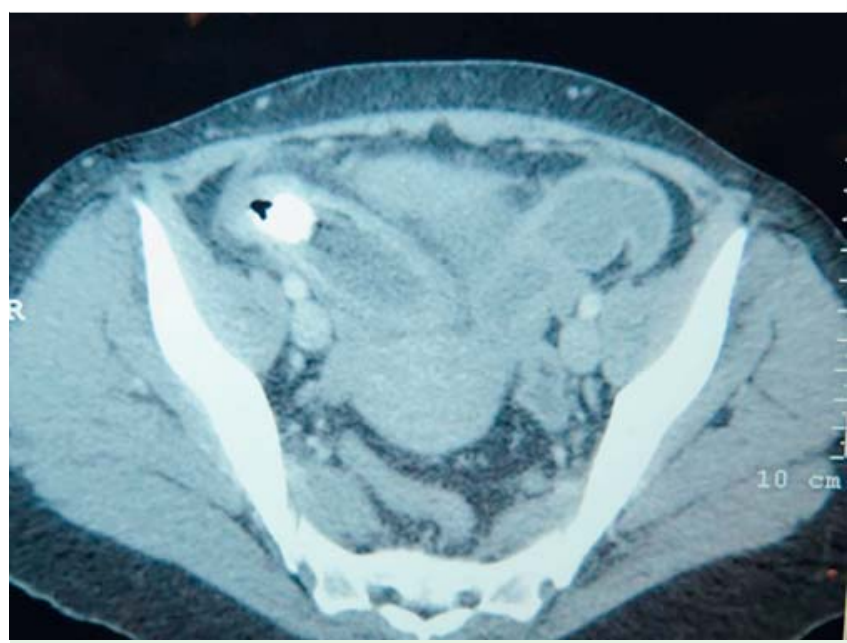

Fig. 3 Abdominal CT: patency capsule in the distal ileum causing an intestinal obstruction.

Subsequent cross-sectional imaging (CT enterography (CTE)/ magnetic resonance enterography (MRE)) was performed in 12 (60\%) patients; in 10/12 (83\%), ileal stenosis was detected. In another two patients, cross-sectional imaging was normal.

Patient details and clinical course are described in detail in $\bullet$ Table 1. 


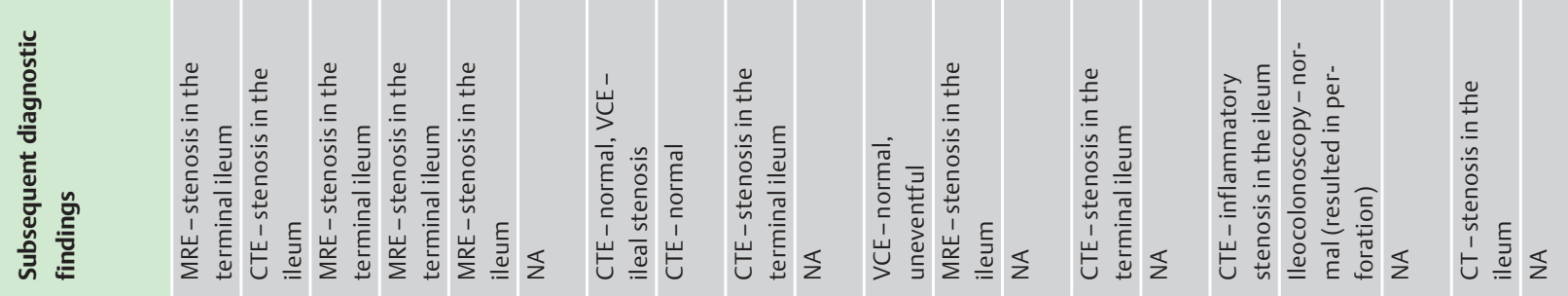

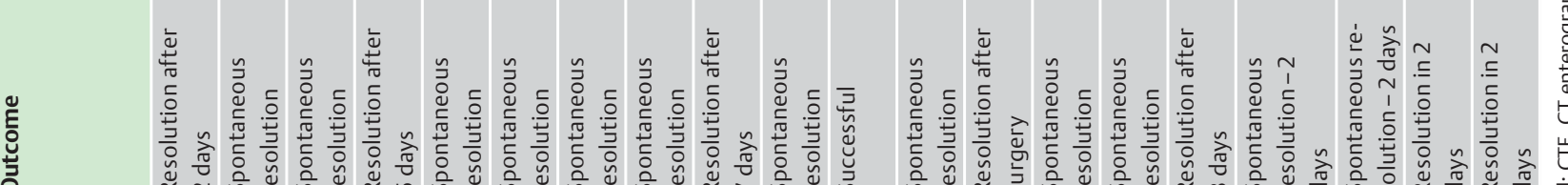

$\frac{10}{2}$

Iมㄴ.

苞
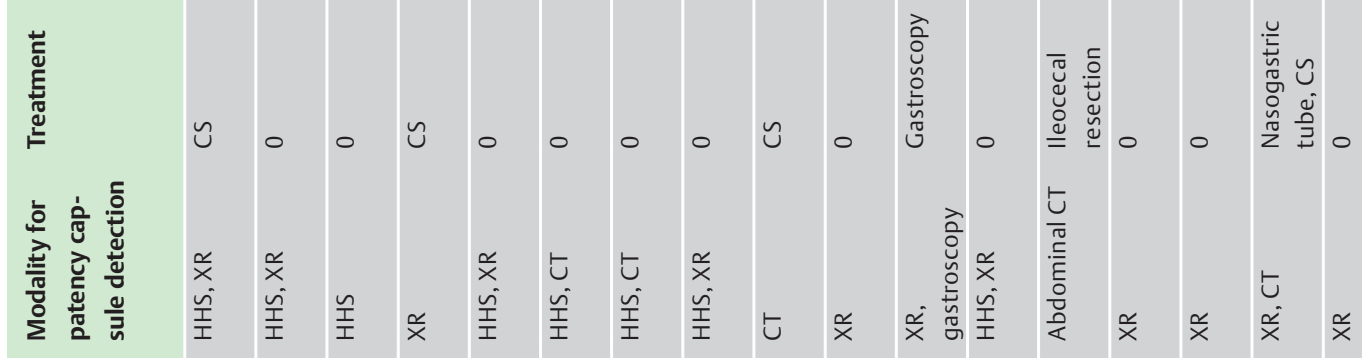

$\stackrel{x}{x}$

$\stackrel{x}{x} \quad \check{x}$

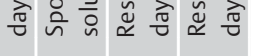

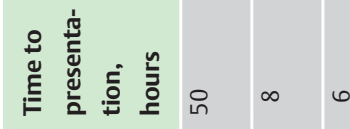

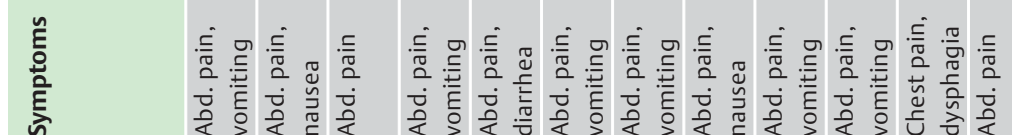

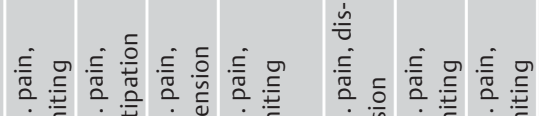

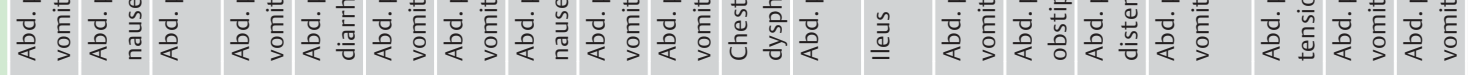

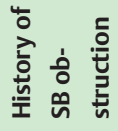

总突

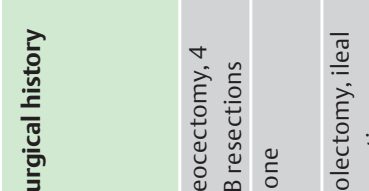

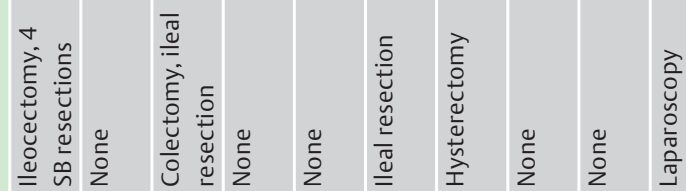

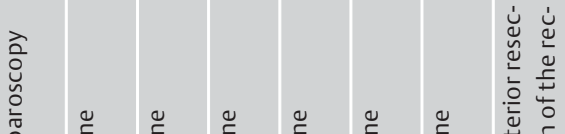

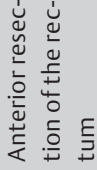

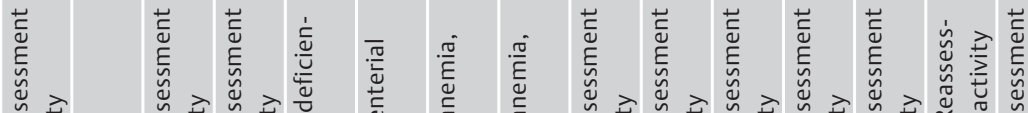

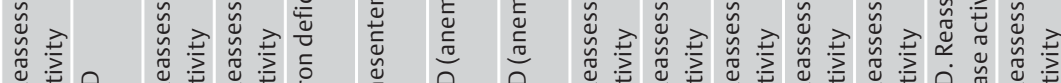

Чٕ

要

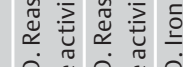

บิ

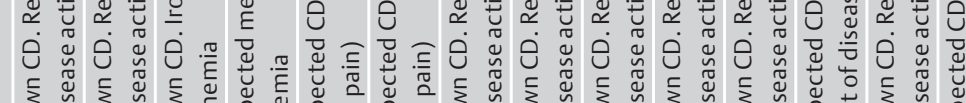

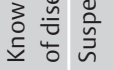

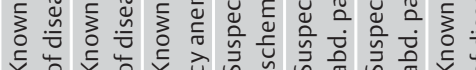

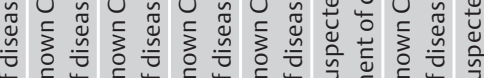

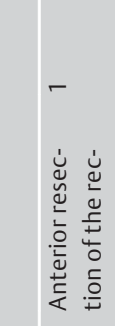

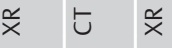

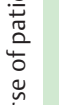

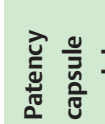

$\therefore$

政

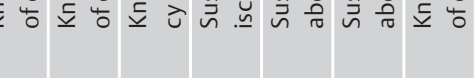

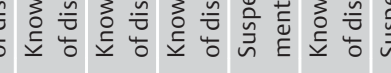

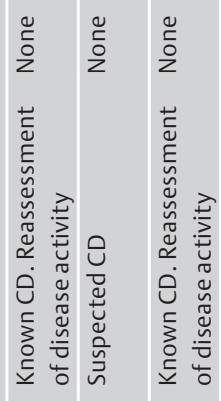

$$
\text { 总 }
$$


Table 2 Adverse effects of the patency capsule in the literature.

\begin{tabular}{|c|c|c|c|c|c|c|}
\hline Reference & $\begin{array}{l}\text { Model of paten- } \\
\text { cy capsule }\end{array}$ & Design & $\begin{array}{l}\text { Patients pre- } \\
\text { senting with ab- } \\
\text { dominal pain }\end{array}$ & Adverse events & $\begin{array}{l}\text { Clinical small- } \\
\text { bowel ob- } \\
\text { struction }\end{array}$ & Treatment \\
\hline Spada et al. [22] & 1st generation & Prospective & $6 / 34(17.64 \%)$ & $\begin{array}{l}\text { Mild: } 5 / 34(14.71 \%) \\
\text { Moderate: } 0 / 34 \\
(0 \%) \text { Severe: } 1 / 34 \\
(2.94 \%)\end{array}$ & $1 / 34(2.9 \%)$ & $\begin{array}{l}\text { Spontaneous recovery: } 5 / 34 \\
(14.71 \%) \\
\text { Medical therapy: } 1 / 34(2.94 \%) \\
\text { Surgery: } 0 / 34(0 \%)\end{array}$ \\
\hline Boivin et al. [25] & 1st generation & Prospective & $6 / 22(27.27 \%)$ & $\begin{array}{l}\text { Mild: } 1 / 22(4.54 \%) \\
\text { Moderate: } 1 / 22 \\
\text { (4.54\%) Severe: } \\
4 / 22(18.18 \%)\end{array}$ & NA & $\begin{array}{l}\text { Spontaneous recovery or medi- } \\
\text { cal therapy: } 5 / 22(22.73 \%) \\
\text { Surgery: } 1 / 22(4.54 \%)\end{array}$ \\
\hline Delvaux et al. [21] & 1st generation & Prospective & $3 / 22(13.64 \%)$ & $\begin{array}{l}\text { Mild: } 1 / 22(4.54 \%) \\
\text { Moderate: } 0 / 22 \\
(0 \%) \text { Severe: } 2 / 22 \\
(9.09 \%)\end{array}$ & $3 / 22(13.6 \%)$ & $\begin{array}{l}\text { Spontaneous recovery: } 1 / 22 \\
(4.54 \%) \\
\text { Medical therapy: } 0 / 22(0 \%) \\
\text { Surgery: } 2 / 22(9.09 \%)\end{array}$ \\
\hline Signorelli et al. [26] & Agile & Prospective & $2 / 32(6.25 \%)$ & $\begin{array}{l}\text { Mild: } 2 / 32(1.44 \%) \\
\text { Moderate: } 0 / 32 \\
(0 \%) \text { Severe: } 0 / 32 \\
(0 \%)\end{array}$ & 0 & $\begin{array}{l}\text { Spontaneous recovery: } 2 / 32 \\
(1.44 \%) \\
\text { Medical therapy: } 0 / 32(0 \%) \\
\text { Surgery: } 0 / 32(0 \%)\end{array}$ \\
\hline Banerjee et al. [27] & 1st generation & Prospective & $0 / 26$ & None & 0 & \\
\hline Spada et al. [28] & 2nd generation & Prospective & $6 / 27(22.22 \%)$ & $\begin{array}{l}\text { Mild: } 5 / 27(18.52 \%) \\
\text { Moderate: } 0 / 27(0 \\
\%) \text { Severe: } 1 / 27 \\
(3.70 \%)\end{array}$ & $1 / 27(3.7 \%)$ & $\begin{array}{l}\text { Spontaneous recovery or medi- } \\
\text { cal therapy: } 5 / 27(18.52 \%) \\
\text { Surgery: } 1 / 27(3.70 \%)\end{array}$ \\
\hline Herrerias et al. [19] & Agile & Prospective & $17 / 106(16 \%)$ & $\begin{array}{l}\text { Mild: } 3 / 106(2.8 \%) \\
\text { Moderate: } 11 / 106 \\
(10.4 \%) \text { Severe: } \\
3 / 106(2.8 \%)\end{array}$ & $1 / 106(0.9 \%)$ & $\begin{array}{l}\text { Spontaneous recovery or medi- } \\
\text { cal therapy: } 16 / 107(15.1 \%) \\
\text { Surgery: } 1 / 106(0.9 \%)\end{array}$ \\
\hline Postgate et al. [29] & Both generations & Retrospective & $0 / 58$ & & & \\
\hline Cohen et al. [30] & 2nd generation & Prospective & $0 / 18$ & & & \\
\hline Yadav et al. [31] & 2nd generation & Prospective & $0 / 42$ & & & \\
\hline Shiotani et al. [32] & 2nd generation & Prospective & $0 / 52$ & & & \\
\hline Nakamura et al. [33] & 2nd generation & Retrospective & $0 / 100$ & & & \\
\hline $\begin{array}{l}\text { Assadsangabi et al. } \\
\text { [34] }\end{array}$ & 2nd generation & Prospective & $\begin{array}{l}\text { Adverse effects } \\
\text { not reported }\end{array}$ & & & \\
\hline Rommele et al. [35] & 2nd generation & retrospective & $0 / 38$ & & & \\
\hline $\begin{array}{l}\text { Albuquerque et al. } \\
\text { [36] }\end{array}$ & 2nd generation & Prospective & $0 / 52$ & & & \\
\hline Total & & & $40 / 629(6.3 \%)$ & & & Surgery: 5/629 (0.8\%) \\
\hline
\end{tabular}

\section{Discussion}

$\nabla$

The patency capsule is an important tool for assessment of smallbowel patency in patients who are at high risk of capsule retention. Utilization of a patency capsule may significantly reduce the risk of SBCE retention [22]. The latest patency capsule model (Agile) was designed to minimize the occurrence of abdominal pain secondary to non-extraction of the patency capsule; the dissolution time of the Agile patency capsule is shorter (30 vs 40 hours) due to the presence of two timer plugs instead of one as designed for the first generation patency capsule, allowing an enhanced contact with intestinal secretions as well as shrinkage of both sides minimizing the chance of obstruction. Complications with a patency capsule are rare and usually manifest as abdominal pain with rare cases of overt bowel obstruction [17-20]. We collected the results of the available prospective studies and case series pertaining to the use of a patency capsule ( Table 2 ). The pooled rate of patency capsule-related complications was 40/629 (6.3\%). The retention resolved spontaneously in 35/40 patients ( $87.5 \%$ ); five patients ( $12.5 \%$ ) required surgery. In addition to abdominal pain and small-bowel obstruction, a single case of intestinal ischemia [23] after patency capsule ingestion was described.
The most probable explanation for patency capsule complications is lodgment of the capsule in a strictured segment of the small bowel, resulting in pain and partial obstruction. In most cases, the capsule dissolves upon contact with intestinal fluids and passes by itself; however, in some cases, such contact may be limited leading to slower dissolution, or even failure to completely dissolve.

The current study is the largest real life case series describing symptomatic patency capsule retention. Almost all of our cases were patients with suspected or established $\mathrm{CD}$. The prevalence of this adverse event was very low. Significant ileal stenosis was demonstrated on cross-sectional imaging in most of the patients. In all but one patient, symptoms resolved without the need for surgery or endoscopy, most probably after patency capsule dissolution. Interestingly, two patients did not have any evidence of small-bowel stenosis on cross-sectional imaging. As these patients were symptomatic and presented with a suspected bowel obstruction, this most probably reflects the limitation of crosssectional imaging for prediction of capsule retention [24,25]. The rate of symptomatic patency capsule retention in our series is the lowest reported even when compared to earlier prospective series, most probably due to the retrospective nature of our 
series that focused on serious adverse events requiring hospitalization. Importantly, even in these severe cases, surgery was required in only one single patient ( $0.6 \%$ of all evaluated patients), obstruction usually resolving spontaneously or with corticosteroid treatment in the majority of cases. One may argue that crosssectional imaging is safer in comparison to a patency capsule to evaluate small-bowel patency, but it is significantly less accurate in the evaluation of functional small-bowel patency, frequently overestimating the risk of obstruction. In a recent study evaluating the accuracy of MRE for prediction of patency capsule retention in patients with established small-bowel $C D$, the sensitivity and specificity of MRE were $92.3 \%$ and 59\%, respectively [24]. Thus, if the decision to administer SBCE had been based on imaging and not patency capsule results, at least $40 \%$ of the patients would have been denied the procedure.

Our study has several limitations. First, this was a retrospective multicenter study. The description of the clinical presentation is limited to the description as presented in the clinical charts at the time. Furthermore, we did not use a quantitative pain evaluation scale. Also, we did not document the shape of the patency capsule on expulsion. Moreover, cross-sectional imaging following patency capsule retention was not routinely available in all patients.

In conclusion, symptomatic patency capsule retention is a very rare adverse event that resolves without surgical or endoscopic intervention in the vast majority of cases. This rare complication should be recognized and acknowledged, but should not discourage physicians from utilization of the patency capsule in patients with suspected small-bowel stenosis before administering SBCE.

Competing interests: Uri Kopylov, Artur Nemeth - none. Anastasios Koulaouzidis - ESGE Given Imaging research grant 2011, Lecture honoraria from Dr Falk Pharma, Travel grant/support from Dr Falk Pharma, Abbott, MSD, Ferring, and material support for research from SynMed UK. Ervin Toth, Rami Eliakim - consulting/speaker's fee from Given Imaging. Ignacio Fernandez-Urien Sainz - consulting fee from Medtronic.

Institutions

Department of Gastroenterology, Chaim Sheba Medical Center, Sackler School of Medicine, Tel-Aviv University, Tel-Aviv, Israel

2 Department of Gastroenterology, Skåne University Hospital, Malmö, Lund University, Sweden

Department of Gastroenterology - NHC, Pamplona, Spain

${ }^{4}$ Endoscopy Unit, Centre for Liver and Digestive Disorders, The Royal Infirmary of Edinburgh, Scotland, UK

\section{References}

1 Pennazio M, Spada C, Eliakim R et al. Small-bowel capsule endoscopy and device-assisted enteroscopy for diagnosis and treatment of smallbowel disorders: European Society of Gastrointestinal Endoscopy (ESGE) Clinical Guideline. Endoscopy 2015; 47: 352 - 376

2 Kopylov $U$, Yablecovitch D, Lahat A et al. Detection of small bowel mucosal healing and deep remission in patients with known small bowel Crohn's disease using biomarkers, capsule endoscopy, and imaging. Am J Gastroenterol 2015; 110: 1316-1323

3 Kopylov U, Ben-Horin S, Seidman EG et al. Video capsule endoscopy of the small bowel for monitoring of Crohn's disease. Inflamm Bowel Dis 2015; 21: 2726-2735

4 Greener T, Klang E, Yablecovitch $D$ et al. The impact of magnetic resonance enterography and capsule endoscopy on the re-classification of disease in patients with known Crohn's disease: A prospective Israeli IBD Research Nucleus (IIRN) study. J Crohns Colitis 2016; 10: 525-531

5 Kopylov U, Seidman EG. Clinical applications of small bowel capsule endoscopy. Clin Exp Gastroenterol 2013; 6: 129-137
6 Cave D, Legnani P, de Franchis $R$ et al. ICCE consensus for capsule retention. Endoscopy 2005; 37: 1065-1067

7 Annese V, Daperno M, Rutter MD et al. European evidence based consensus for endoscopy in inflammatory bowel disease. J Crohns Colitis 2013; 7: $982-1018$

8 Nemeth A, Kopylov U, Koulaouzidis A et al. Use of patency capsule in patients with established Crohn's disease. Endoscopy 2016; 48: 373 - 379

9 Mow WS, Lo SK, Targan SR et al. Initial experience with wireless capsule enteroscopy in the diagnosis and management of inflammatory bowel disease. Clin Gastroenterol Hepatol 2004; 2: 31 -40

10 Cheifetz AS, Kornbluth AA, Legnani $P$ et al. The risk of retention of the capsule endoscope in patients with known or suspected Crohn's disease. Am J Gastroenterol 2006; 101: 2218 - 2222

11 Kopylov U, Nemeth A, Koulaouzidis A et al. Small bowel capsule endoscopy in the management of established Crohn's disease: Clinical impact, safety, and correlation with inflammatory biomarkers. Inflamm Bowel Dis 2015; 21: $93-100$

12 Niv E, Fishman S, Kachman $H$ et al. Sequential capsule endoscopy of the small bowel for follow-up of patients with known Crohn's disease. J Crohns Colitis 2014; 8: 1616-1623

13 Hall BJ, Holleran GE, Smith SM et al. A prospective 12-week mucosa healing assessment of small bowel Crohn's disease as detected by capsule endoscopy. Eur J Gastroenterol Hepatol 2014; 26: 1253 - 1259

14 Hall B, Holleran G, Chin JL et al. A prospective 52 week mucosal healing assessment of small bowel Crohn's disease as detected by capsule endoscopy. J Crohns Colitis 2014; 8: 1601 -1609

15 Flamant $M$, Trang C, Maillard $O$ et al. The prevalence and outcome of jejunal lesions visualized by small bowel capsule endoscopy in Crohn's disease. Inflamm Bowel Dis 2013; 19: 1390 - 1396

16 Esaki M, Matsumoto T, Watanabe $K$ et al. Use of capsule endoscopy in patients with Crohn's disease in Japan: a multicenter survey. J Gastroenterol Hepatol 2014; 29: 96-101

17 Caunedo-Alvarez A, Romero-Vazquez J, Herrerias-Gutierrez JM. Patency and Agile capsules. World J Gastroenterol 2008; 14: 5269-5273

18 Kato S, Osada H, Yakabi K. A rare case of temporary intestinal obstruction induced by the novel tag-less Agile patency capsule in a patient with Crohn's disease. Dig Endosc 2016; 28: 481

19 Herrerias JM, Leighton JA, Costamagna $G$ et al. Agile patency system eliminates risk of capsule retention in patients with known intestinal strictures who undergo capsule endoscopy. Gastrointest Endosc 2008; 67: $902-909$

20 Liatsos C, Kyriakos N, Panagou E et al. An unusual presentation of obstructive ileus, due to impacted Agile patency capsule, in a patient with Crohn's disease. Ann Gastroenterol 2011; 24: 65-66

21 Delvaux M, Ben Soussan E, Laurent Vet al. Clinical evaluation of the use of the M2A patency capsule system before a capsule endoscopy procedure, in patients with known or suspected intestinal stenosis. Endoscopy 2005; 37: $801-807$

22 Spada C, Spera G, Riccioni $M$ et al. A novel diagnostic tool for detecting functional patency of the small bowel: the Given patency capsule. Endoscopy 2005; 37: 793-800

23 Okoli A, Ammannagari N, Mazumder M et al. When the dissolvable does not dissolve: an agile patency capsule mystery. Am J Gastroenterol 2014; 109: 605-607

24 Rozendorn N, Klang E, Lahat A et al. Prediction of patency capsule retention in known Crohn's disease patients using magnetic resonance imaging. Gastrointest Endosc 2016; 83: 182 - 187

25 Boivin ML, Lochs H, Voderholzer WA. Does passage of a patency capsule indicate small-bowel patency? A prospective clinical trial Endoscopy 2005; 37: 808-815

26 Signorelli C, Rondonotti E, Villa F et al. Use of the Given Patency System for the screening of patients at high risk for capsule retention. Dig Liver Dis 2006; 38: $326-330$

27 Banerjee R, Bhargav P, Reddy P et al. Safety and efficacy of the M2A patency capsule for diagnosis of critical intestinal patency: results of a prospective clinical trial. J Gastroenterol Hepatol 2007; 22: 20602063

28 Spada C, Shah SK, Riccioni ME et al. Video capsule endoscopy in patients with known or suspected small bowel stricture previously tested with the dissolving patency capsule. J Clin Gastroenterol 2007; 41: $576-582$

29 Postgate AJ, Burling D, Gupta A et al. Safety, reliability and limitations of the given patency capsule in patients at risk of capsule retention: a 3year technical review. Dig Dis Sci 2008; 53: 2732 - 2738 
30 Cohen SA, Gralnek IM, Ephrath $H$ et al. The use of a patency capsule in pediatric Crohn's disease: a prospective evaluation. Dig Dis Sci 2011; 56: $860-865$

31 Yadav A, Heigh RI, Hara AK et al. Performance of the patency capsule compared with nonenteroclysis radiologic examinations in patients with known or suspected intestinal strictures. Gastrointest Endosc 2011; 74: 834-839

32 Shiotani A, Hata J, Manabe $N$ et al. Clinical relevance of patency capsule combined with abdominal ultrasonography to detect small bowel strictures. Eur J Gastroenterol Hepatol 2014; 26: 1434-1438

33 Nakamura M, Hirooka Y, Yamamura T et al. Clinical usefulness of novel tag-less Agile patency capsule prior to capsule endoscopy for patients with suspected small bowel stenosis. Dig Endosc 2015; 27: 61 -66
34 Assadsangabi A, Blakeborough A, Drew K et al. Small bowel patency assessment using the patency device and a novel targeted (limited radiation) computed tomography-based protocol. J Gastroenterol Hepatol 2015; 30: $984-989$

35 Rommele C, Brueckner J, Messmann $\mathrm{H}$ et al. Clinical experience with the PillCam patency capsule prior to video capsule endoscopy: a realworld experience. Gastroenterol Res Pract 2016; 2016: 9657053 (Epub 2016 Jan 6) DOI 10.1155/2016/9657053

36 Albuquerque A, Cardoso H, Marques $M$ et al. Predictive factors of small bowel patency in Crohn's disease patients. Rev Esp Enferm Dig 2016; 108: $65-70$ 